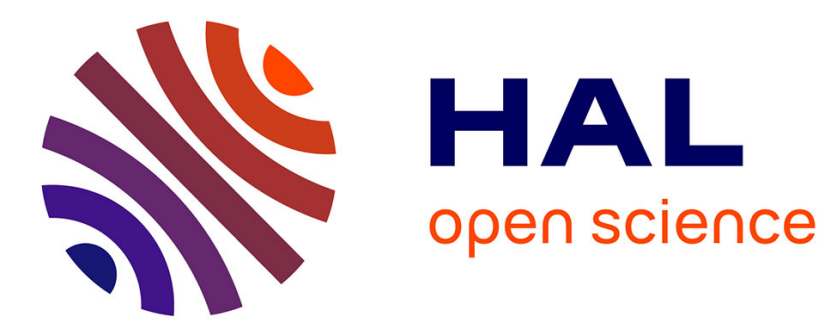

\title{
A transmission electron microscopy study of phase compatibility in low hysteresis shape memory alloys
}

Remi Delville, Sakthivel Kasinathan, Zhiyong Zhang, V Humbeeck, Richard Dick James, Dominique Schryvers

\section{- To cite this version:}

Remi Delville, Sakthivel Kasinathan, Zhiyong Zhang, V Humbeeck, Richard Dick James, et al.. A transmission electron microscopy study of phase compatibility in low hysteresis shape memory alloys. Philosophical Magazine, 2010, 90 (01-04), pp.177-195. 10.1080/14786430903074755 . hal-00556063

\section{HAL Id: hal-00556063 https://hal.science/hal-00556063}

Submitted on 15 Jan 2011

HAL is a multi-disciplinary open access archive for the deposit and dissemination of scientific research documents, whether they are published or not. The documents may come from teaching and research institutions in France or abroad, or from public or private research centers.
L'archive ouverte pluridisciplinaire HAL, est destinée au dépôt et à la diffusion de documents scientifiques de niveau recherche, publiés ou non, émanant des établissements d'enseignement et de recherche français ou étrangers, des laboratoires publics ou privés. 


\section{A transmission electron microscopy study of phase compatibility in low hysteresis shape memory alloys}

\begin{tabular}{|c|c|}
\hline Journal: & Philosophical Magazine \& Philosophical Magazine Letters \\
\hline Manuscript ID: & TPHM-08-Nov-0423.R1 \\
\hline Journal Selection: & Philosophical Magazine \\
\hline $\begin{array}{r}\text { Date Submitted by the } \\
\text { Author: }\end{array}$ & 07-Apr-2009 \\
\hline Complete List of Authors: & $\begin{array}{l}\text { Delville, Remi; University of Antwerp, Physics } \\
\text { Kasinathan, Sakthivel; University of Minnesota, Aerospace } \\
\text { Engineering and Mechanics } \\
\text { Zhang, Zhiyong; University of Minnesota, Aerospace Engineering } \\
\text { and Mechanics } \\
\text { Humbeeck, V; KU Leuven, MTM } \\
\text { James, Richard; University of Minnesota, Aerospace Engineering } \\
\text { and Mechanics } \\
\text { Schryvers, Dominique; University of Antwerp, Physics }\end{array}$ \\
\hline Keywords: & electron microscopy, interfaces, martensitic transformations \\
\hline Keywords (user supplied): & hysteresis \\
\hline
\end{tabular}

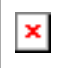




\title{
A transmission electron microscopy study of phase compatibility in low hysteresis shape memory alloys
}

\author{
Rémi Delville $^{\mathrm{a},{ }^{*}}$, Sakthivel Kasinathan ${ }^{\mathrm{b}}$, Zhiyong Zhang ${ }^{\mathrm{b}}$, Jan Van Humbeeck ${ }^{\mathrm{c}}$, Richard D. James ${ }^{\mathrm{b}}$ and Dominique \\ Schryvers $^{\mathrm{a}}$ \\ ${ }^{\text {a} E l e c t r o n ~ M i c r o s c o p y ~ f o r ~ M a t e r i a l s ~ S c i e n c e ~(E M A T), ~ U n i v e r s i t y ~ o f ~ A n t w e r p, ~ G r o e n e n b o r g e r l a a n ~ 171, ~ B-2020 ~}$ \\ Antwerp, Belgium \\ ${ }^{\mathrm{b}}$ Department of Aerospace Engineering and Mechanics, University of Minnesota, Minneapolis, Minnesota 55455, \\ USA \\ ${ }^{\mathrm{c}}$ Department MTM, Catholic University of Leuven, de Croylaan 2, B-3001 Heverlee, Belgium \\ *Corresponding author. Email: remi.delville@ua.ac.be
}

\begin{abstract}
Recent findings have linked low hysteresis in shape memory alloys with phase compatibility between austenite and martensite. In order to investigate the evolution of microstructure as the phase compatibility increases and the hysteresis is reduced, transmission electron microscopy was used to study the alloy system $\mathrm{Ti}_{50} \mathrm{Ni}_{50-\mathrm{x}} \mathrm{Pd}_{\mathrm{x}}$ where the composition is systemically tuned to approach perfect compatibility. Changes in morphology, twinning density and twinning modes are reported along with special microstructures occurring when the compatibility is achieved. In addition, the interface between austenite and a single variant of martensite was studied by highresolution and conventional electron microscopy. The low energy configuration of the interface detailed in this article suggests that it plays an important role in the lowering of hysteresis compared to classical habit plane interfaces.
\end{abstract}

Keywords: electron microscopy; martensitic transformation; interfaces; hysteresis 


\section{Introduction}

Hysteresis in shape memory alloys (SMA) plays an important role in their thermo-mechanical behavior with important technological consequences in the design and operation of these materials. Hysteresis is the macroscopic manifestation of the energy dissipated during a phase transformation. One mechanism of dissipation is the creation of defects that accumulate during cycling to eventually become the sites of crack initiation [1]. In such cases hysteresis also correlates with fatigue, an important parameter for applications, especially for systems subjected to cyclic loading. The sources of hysteresis and their relative importance are not yet fully understood because of their actions at different spatial scales [2] and their possible interdependence. At the microscopic scale both the nucleation of the new phase and the interactions of interfaces with defects contribute to the hysteresis. At larger scales, interactions between domains as well as heat transfer play a role. Recent findings [1] however suggest that interactions at interfaces between the martensitic and austenitic phases during phase transformation might be the dominant phenomenon contributing to hysteresis. This result is supported by the latest development in the geometric nonlinear theory of martensite (GLNTM) $[3,4]$ which explains the formation of martensite microstructures, the shape memory effect and the role of crystalline symmetry and phase compatibilities. This theory gives several conditions in order for SMAs to show extremely low hysteresis $[1,3,5]$. The first condition is no volume change during phase transformation which in mathematical term translates to $\operatorname{det}(U)=\lambda_{1} \lambda_{2} \lambda_{3}=1$, where $U$ is the positive-definite, symmetric transformation matrix that maps the martensite lattice to the austenite lattice, $\operatorname{det}(U)$ is the determinant and $\lambda_{1} \leq \lambda_{2} \leq \lambda_{3}$ are the ordered eigenvalues of $U$. The second condition $\lambda_{2}=1$ is necessary and sufficient so that there is a perfect interface - unstressed and untwined - between austenite and martensite. This is referred in the 
text as phase compatibility. The six transformation matrices $U_{1}-U_{6}$ for the cubic (B2) to orthorhombic (B19) phase transformation are shown in Equation 1. Their values are entirely determined by the lattice parameters of the austenite $\left(a_{0}\right)$ and martensite phases $(a, b, c)$.

$$
\begin{aligned}
& U_{1}=\left(\begin{array}{ccc}
\beta & 0 & 0 \\
0 & \frac{\alpha-\gamma}{2} & \frac{\alpha+\gamma}{2} \\
0 & \frac{\alpha+\gamma}{2} & \frac{\alpha-\gamma}{2}
\end{array}\right) U_{2}=\left(\begin{array}{ccc}
\beta & 0 & 0 \\
0 & \frac{\gamma-\alpha}{2} & \frac{\alpha+\gamma}{2} \\
0 & \frac{\alpha+\gamma}{2} & \frac{\gamma-\alpha}{2}
\end{array}\right) \\
& U_{3}=\left(\begin{array}{ccc}
\frac{\alpha-\gamma}{2} & 0 & \frac{\alpha+\gamma}{2} \\
0 & \beta & 0 \\
\frac{\alpha+\gamma}{2} & 0 & \frac{\alpha-\gamma}{2}
\end{array}\right) U_{4}=\left(\begin{array}{ccc}
\frac{\gamma-\alpha}{2} & 0 & \frac{\alpha+\gamma}{2} \\
0 & \beta & 0 \\
\frac{\alpha+\gamma}{2} & 0 & \frac{\gamma-\alpha}{2}
\end{array}\right) \\
& U_{5}=\left(\begin{array}{ccc}
\frac{\gamma-\alpha}{2} & \frac{\alpha+\gamma}{2} & 0 \\
\frac{\alpha+\gamma}{2} & \frac{\gamma-\alpha}{2} & 0 \\
0 & 0 & \beta
\end{array}\right) U_{6}=\left(\begin{array}{ccc}
\frac{\gamma-\alpha}{2} & \frac{\alpha+\gamma}{2} & 0 \\
\frac{\alpha+\gamma}{2} & \frac{\gamma-\alpha}{2} & 0 \\
0 & 0 & \beta
\end{array}\right) \\
& \beta=\lambda_{1}=\frac{a}{a_{0}} \quad \alpha=\lambda_{2}=\frac{b}{\sqrt{2} a_{0}} \quad \gamma=\lambda_{3}=\frac{c}{\sqrt{2} a_{0}}
\end{aligned}
$$

When Cui et al. [1] investigated the dependence of hysteresis with these two parameters on composition-spread $\mathrm{TiNiCu}$ and TiNiPd thin films, they discovered a strong correlation between hysteresis and $\lambda_{2}$, but not with $\operatorname{det}(U)$. The same correlation was confirmed by Zhang et al. [6] for bulk alloys of TiNiAu, TiNiPd and TiNiPt. Figure 1 shows the evolution of hysteresis as a function of $\lambda_{2}$ for the $\mathrm{Ti}_{50} \mathrm{Ni}_{50-\mathrm{x}} \mathrm{Pd}_{\mathrm{x}}$ bulk alloys used for the present TEM investigation. The hysteresis decreases as $\lambda_{2}$ approaches 1 and is minimal when perfect compatibility is achieved $\left(\mathrm{Ti}_{50} \mathrm{Ni}_{40} \mathrm{Pd}_{10}\right.$ and $\left.\mathrm{Ti}_{50} \mathrm{Ni}_{39} \mathrm{Pd}_{11}\right)$. These data were also reported in [6] except for the $\mathrm{Ti}_{50} \mathrm{Ni}_{40} \mathrm{Pd}_{10}$ alloy. Similar plots were obtained for the TiNiAu, TiNiPt and TiNiCu systems in bulk or thin films as shown in [6].

This finding underlines the importance of phase compatibility for hysteresis which seems to follow a universal behavior as a function of $\lambda_{2}$. A typical interface between the austenitic phase and martensitic phase in an alloy with $\lambda_{2} \neq 1$ is shown Figure $2[7,8]$. Since a single variant of martensite is not compatible with the parent phase, the microstructure accommodates the 
interface with a laminate of two variants to minimize energy. The interface as seen in Figure 2 is neither sharp nor particularly well defined and a large transition layer with tapering of twins is visible. One can already foresee from this picture that such an interface will induce some strain especially in the twinned martensite. This was confirmed by Sun et al. $[9,10]$ who used Moiré interferometry pattern at an austenite-martensite interface in CuAlNi and found a high number of fringes in the martensite revealing a high level of strain. It also shows that on the scale allowed by the resolution of the technique, the deformation is homogenous with a constant deformation gradient. At the scale of atomic resolution transmission electron microscopy techniques like geometric phase analysis allow one to map strain fields around precipitates or at interfaces, as attempted by Hÿtch et al. for a coherent microtwinned interface in $\mathrm{Cu}-\mathrm{Zn}-\mathrm{Al}$ [11].

The idea behind hysteresis is that the main energy barrier of the phase transformation arises from the bulk energy of this transition layer and the interfacial energy of the twin bands. The growth of a fully developed austenite-martensite interface is costly in energy but it can be greatly reduced by making martensite and austenite compatible. The study with electron microscopy of low hysteresis alloys near compatibility is therefore an important source of information to understand the impact of phase compatibility on the microstructure and how it relates to low hysteresis. The $\mathrm{Ti}_{50} \mathrm{Ni}_{50-\mathrm{x}} \mathrm{Pd}_{\mathrm{x}}$ system was chosen because its composition can be tuned to achieve the condition $\lambda_{2}=1$, where it shows a very small hysteresis, and it can be easily prepared for TEM investigation.

\section{Experimental}

Alloys were prepared from pure elements (99.98 mass\% Ti, 99.995 mass\% Ni, 99.95 mass\% Pd) by arc melting in an argon atmosphere. Slabs of $1 \mathrm{~mm}$ or less in thickness were cut from the 
ingot by EDM (Electrical Discharge Machining) and subsequently homogenized at $1373 \mathrm{~K}$ during 20ks followed by quenching in room-temperature water. Lattice parameters of both martensite and austenite were measured on a Scintag X-ray diffractometer on polycrystalline slabs previously chemically etched using an electrolyte of $85 \% \mathrm{CH}_{3} \mathrm{COOH}$ and $15 \% \mathrm{HClO}_{4}$. Transformation temperatures and hysteresis were measured by differential scanning calorimetry (DSC) on a TA Instruments Q1000 with $100 \mu \mathrm{m}$ thick slabs, previously etched by the same method. For the TEM study, disks of $3 \mathrm{~mm}$ in diameter were spark-cut or slurry drilled from the slabs, mechanically polished to a $200 \mu \mathrm{m}$ thickness and finally electropolished to perforation in a Tenupol 3 operated at $12 \mathrm{~V}, 0.1 \mathrm{~A}, 253 \mathrm{~K}$ with an electrolyte of $80 \% \mathrm{CH}_{3} \mathrm{OH}$ and $20 \% \mathrm{H}_{2} \mathrm{SO}_{4}$. Conventional transmission electron microscopy (CTEM) observations were carried out in a Phillips CM20 microscope operated at $200 \mathrm{kV}$ using a side-entry type double-tilt specimen holder with angular ranges of $+/-45^{\circ}$. High resolution electron microscopy (HREM) and CTEM observations were carried out in a FEG Phillips CM30 microscope operated at $300 \mathrm{kV}$ using a side-entry type double-tilt specimen holder.

The $\mathrm{Ti}_{50} \mathrm{Ni}_{50-\mathrm{x}} \mathrm{Pd}_{\mathrm{x}}$ system undergoes a martensitic transformation on cooling from a cubic (B2) to an orthorhombic (B19) lattice for compositions above $x=7[12,13]$. This transformation gives rise to 6 variants of martensite, denoted 1 to 6 . Each of the possible transformations can be described by its own transformation strain matrix, $U_{1}-U_{6}$, as listed in Equation 1. Lattice parameters of austenite $\left(a_{0}\right)$ and martensite $(a, b, c)$, listed in Table 1 for the different compositions studied, were measured on a Scintag X-ray diffractometer outfitted with a temperature controlled stage. Special attention was paid to alignment by using internal standard (NIST standard reference 640c) and periodically doing in-situ alignment at different temperatures. The arc-melted, solution-treated alloys have an average grain size of $100 \mu \mathrm{m}$. A 
modified Rietveld procedure was used for refinement. The standard error on the determination of lattice parameters was estimated to $+/-1.10^{-3} \AA$. The middle eigenvalue $\lambda_{2}$ was directly calculated from the lattice parameters. The standard error on $\lambda_{2}$ is $+/-5.10^{-4}$. In addition, Table 2 shows the average value of the four characteristic transformation temperatures $\theta_{c}=\left(A_{s}+A_{f}+M_{s}+M_{f}\right) / 4$ and the thermal hysteresis defined as the difference between the average transformation temperature of the austenitic and martensitic transformation, i.e. $H=\left(A_{s}+A_{f}-M_{s}-M_{f}\right) / 2$.

Variants are associated in pairs to form twins. The pairs 1-2, 3-4, 5-6 have a compound twin connection and all other pairs (e.g., 1-3) have type I / type II twin connections. Table 2 shows the twin parameters for three selected alloys calculated with the GNLTM. $K_{l}$ is the twinning plane and $\eta_{1}$ the shear direction. There are three twinning modes, $\{111\}$ type I, $<211>$ type II and \{011\} compound. Only the values of the irrational planes and directions depend on the composition. It has been shown that, in the frame of the GNLTM $[6,14]$, type I/II twins cannot participate in the austenite-martensite interface when $\lambda_{2}<1$ and conversely compound twins cannot participate when $\lambda_{2}>1$. For this reason the twin ratio $\lambda$, defined such that $\lambda(1-\lambda)$ is the volume fraction of the smaller variant participating in the austenite-martensite interface, only has meaning when these conditions are satisfied. The closer is $\lambda_{2}$ to 1 , the smaller is the twin ratio $\lambda$.

\section{Results and discussions}

\subsection{Evolution of the microstructure}

Figure 3(a)-(c) shows the evolution of martensite morphology as the content of Pd is decreased towards the compatibility condition $\lambda_{2}=1$. The alloy with the highest $\mathrm{Pd}$ content, $\mathrm{Ti}_{50} \mathrm{Ni}_{25} \mathrm{Pd}_{25}$, has a $\lambda_{2}=1.0070$, the largest value in the series studied. Its morphology (Figure 3(a)) is one commonly found in SMAs with long martensite plates constituted of parallel planar layers of 
twinned martensite variants sometimes referred to as twin laminates. The twin laminates extend diagonally across the width of the martensite plates with rather regular spacing. Their orientations alternate between configuration A and B in successive plates ((Figure 3(a)). The same relative orientation between successive plates was found throughout the sample. Selected Area Diffraction (SAD) patterns in Figures 3(d) and 3(e) were taken from the twin laminates in plates A and B (Figure 3(a)) in two different orientations, the beam edge-on with the twinning plane. Each pattern consists of two sets of reflections which are in mirror symmetry with respect to the (111) plane. The same $\{111\}$ type I twin is found throughout the sample and is considered to be the lattice invariant shear (LIS) which means that martensite is sheared along this mode to accommodate a habit plane with austenite during the phase transformation. Same morphology and LIS twinning of the laminates were reported for higher Pd content $[15,16]$.

As the content of $\mathrm{Pd}$ decreases, so does $\lambda_{2} \cdot \mathrm{Ti}_{50} \mathrm{Ni}_{30} \mathrm{Pd}_{20}\left(\lambda_{2}=1.0050\right)$ shows some significant changes in its microstructure compared to higher Pd alloys. The lamellar morphology of the martensite plates is partly retained but many plates now exhibit a lower twin ratio or even no twinning. Figure 3(b) is a bright field micrograph of a martensite plate in $\mathrm{Ti}_{50} \mathrm{Ni}_{30} \mathrm{Pd}_{20}$ showing a lower twin ratio than in $\mathrm{Ti}_{50} \mathrm{Ni}_{25} \mathrm{Pd}_{25}$. In addition, the surrounding plates do not show any twinning. Overall, the microstructure has a more disorganized morphology, a feature amplified in $\mathrm{Ti}_{50} \mathrm{Ni}_{39} \mathrm{Pd}_{11}$.

$\mathrm{Ti}_{50} \mathrm{Ni}_{39} \mathrm{Pd}_{11}$ has one of the lowest hysteresis from the series shown in Figure 3 and a $\lambda_{2}=1.0001$, meaning that virtually no lattice invariant shear is required for an undistorted plane (habit plane) to exist during transformation. This compatibility between a single variant of martensite and the austenite matrix allows for twinless transformation that minimizes the overall energy of interfaces, leading to a lower hysteresis. Figure 3(c) shows an example of microstructure 
commonly observed in $\mathrm{Ti}_{50} \mathrm{Ni}_{39} \mathrm{Pd}_{11}$. It is composed of a mosaic of microns-wide twinless martensite plates as noted by E, F, G, H in Figure 3(c). The absence of twin laminates inside the plates was also reported for $\mathrm{Ti}_{79} \mathrm{Ta}_{21}$ [17], $\mathrm{Ti}_{49.5} \mathrm{Ni}_{40.5} \mathrm{Cu}_{10}[18,19]$ and $\mathrm{Ti}_{50} \mathrm{Ni}_{30} \mathrm{Cu}_{20}$ [20], which also have a $\lambda_{2}$ close to 1 .

(111) type I LIS twin laminates observed for the higher $\mathrm{Pd}$ content are a product of the accommodation of martensite at the interface with austenite during phase transformation. Plates of martensite will only grow as laminates of two variants since a single variant is not compatible with the austenite. But when perfect compatibility is satisfied, as for Pd content around 11 at.\%, plates composed of a single variant can develop. The resulting microstructure is determined by the local nucleation conditions and the ensuing growth of martensite plates. One process shaping the microstructure consists in the simultaneous growth of several mono-variant plates from one nucleation site in a self-accommodated group of plates (SAG) morphology in order to minimize the transformation strain. SAGs are also observed in $\lambda_{2} \neq 1$ alloys such as binary Ni-Ti [21, 22]. In that case, the SAGs are composed of laminated martensite plates that accommodate an interface with austenite during growth. Typical triangular SAGs as described by Saburi et al. [23] in $\mathrm{TiNiCu}$ were observed in $\mathrm{Ti}_{50} \mathrm{Ni}_{39} \mathrm{Pd}_{11}$ and reported in [24]. Another possible process shaping the microstructure may be the impingement of plates (or SAG) that have nucleated at different locations. Boullay et al. [25] have shown for $\mathrm{Ni}_{65} \mathrm{Al}_{35}$ martensite that impinging laminar plates not corresponding with orientations appearing in SAGs undergo a small rotation in order to meet along an energy-minimizing interface. In the case of $\lambda_{2}=1$ alloys, single variants will impinge on each other and their interface may form a twin boundary after a small rotation. The twin type would then depend on the pair of variants under consideration. The three types of possible twins, namely (011) compound (Figure 3(c)), (111) type I and <211> type II (Figure 4(a)) where found 
in $\mathrm{Ti}_{50} \mathrm{Ni}_{39} \mathrm{Pd}_{11}$. Figure 4(a) illustrates an area in $\mathrm{Ti}_{50} \mathrm{Ni}_{39} \mathrm{Pd}_{11}$ which could have been possibly formed along the two mechanisms described above. The boundaries noted B and C are $\{111\}$ type I twin and are formed by three variants in a triangular SAG in accordance with the model proposed by Saburi et al. [23]. A $<211>$ type II interface was found in the interface noted D and could have been created through the impingement of plates.

It has also been observed that the largest mono-variant martensite plates are present in areas free of defects and precipitates where they were able to grow unconstrained. Areas containing $\mathrm{Ti}_{2} \mathrm{Ni}(\mathrm{Pd})$ precipitates or defects contain smaller plates and a higher density of interfaces since martensite had to accommodate local stress fields and since the number of nucleation sites is potentially higher.

It is worth here mentioning that this special microstructure is not limited at $\mathrm{Ti}_{50} \mathrm{Ni}_{39} \mathrm{Pd}_{11}$, it has been observed in alloys with a slight difference in composition but with a $\lambda_{2}$ remaining close to 1 (roughly in the range $\lambda_{2}=1.000+/-0.004$ ) such as $\mathrm{Ti}_{50} \mathrm{Ni}_{41} \mathrm{Pd}_{9}$ and in some parts of $\mathrm{Ti}_{50} \mathrm{Ni}_{32} \mathrm{Pd}_{18}$ or even $\mathrm{Ti}_{50} \mathrm{Ni}_{30} \mathrm{Pd}_{20}$. One has to be aware that the value of $\lambda_{2}$ is derived from $\mathrm{X}$-ray measurements, which averages lattice parameters over the bulk. Local variations of composition in the bulk sample, hence local variations of lattice parameters are not to be excluded and could explain why certain types of twins appear in certain areas, whereas large twinless plates appear in others. In addition certain samples contain a small quantity of $\mathrm{Ti}_{2} \mathrm{Ni}(\mathrm{Pd})$ precipitates which locally alter the composition of the surrounding matrix as confirmed by EDS measurements. However, compositional or lattice parameter variations within the matrix, away from precipitates could not be confirmed by EDS or EELS spectroscopy and LACBED, respectively. Also, since the averaged austenite grain size measured from X-ray diffraction as well as the size of the resulting martensite plates as observed in TEM does not show large variations between the 
different compositions, no grain nor plate size effect as found in, e.g., $\mathrm{Ni}_{\mathrm{x}} \mathrm{Al}_{100-\mathrm{x}}$ samples with different composition or thermo-mechanical history [26], is expected in the present case.

\subsection{Austenite-martensite interface}

To gain further insights into the mechanism of transformation with phase compatibility, it is necessary to study the austenite (B2) / martensite (B19) interface. $\mathrm{Ti}_{50} \mathrm{Ni}_{40} \mathrm{Pd}_{10}$ presents the proper conditions for such study. First of all, its transformation temperatures lie near room temperature, thus allowing the simultaneous observation of martensite, austenite and their common interfaces. Secondly, with a $\lambda_{2}=0.9998+/-0.0005, \mathrm{Ti}_{50} \mathrm{Ni}_{40} \mathrm{Pd}_{10}$ satisfies exactly the compatibility condition within the error bar and shows the smallest hysteresis of the series, measured at $6 \mathrm{~K}$ from the DSC curve presented in Figure 5. A sample of $6.2 \mathrm{mg}$ was mounted on a differential scanning calorimeter (DSC Q2000-TA instruments). The sample was cycled two times between $220 \mathrm{~K}$ and $370 \mathrm{~K}$ at a heating and cooling rate of $5 \mathrm{~K} / \mathrm{min}$. No difference was observed between both cycles.

From the DSC graph (Figure 5), the temperatures of the peak-maxima related to the reverse (heating) and forward (cooling) transformation show a hysteresis of about $6 \mathrm{~K}$. A heat-flow of about $16 \mathrm{~J} / \mathrm{g}$ was calculated for both reverse and forward transformation.

The $\mathrm{Ti}_{50} \mathrm{Ni}_{40} \mathrm{Pd}_{10}$ samples prepared for TEM were usually composed of an austenite matrix within which a few plates of martensite had nucleated. It was however possible to increase the number and size of the martensite plates by cooling the sample before and during the thinning by electropolishing.

Figure 6(a) shows a typical arrangement of martensite plates embedded in an austenite matrix. The microstructure comprises two groups of parallel martensite lamellas noted A and B. Each 
group of plates forms interfaces with austenite along a common habit plane. This plane is rotated $90^{\circ}$ between groups A and B. SAD patterns taken over the circled areas A and B in Figure 6(a) are shown in Figure 6(b) and 6(e), respectively. Both show two sets of reflections. One belongs to the $\mathrm{B} 2$ matrix orientated in the [011] direction and the other to the B19 phase in a [010] zone axis. The common $[010]_{\mathrm{B} 19}$ zone axis entails that the groups of martensite plates in area A and B belong to the same variant since no variants in the cubic to orthorhombic phase transformation share a common [010] axis. The sets of B2 reflections (red in 6(d) and (g)) coming from the austenite matrix share the same position in both patterns. The set of B19 reflections (black in 6(d) and (g)) is slightly rotated clockwise in area A and counter-clockwise in area B, relatively to the B2 set. To understand this observation, a simulation of the interfaces has been carried out.

First of all, the possible habit planes are calculated from the fundamental compatibility equation of the GNLTM (Equation 2).

$$
Q U_{i}-I=a \otimes n
$$

where $\boldsymbol{U}_{i}$ is the transformation matrix of variant $i(i=1, \ldots, 6), \mathrm{I}$ is the identity matrix representing the austenite, $Q$ is a rotation matrix, $a$ is the direction of shear and $n$ is the normal vector of the habit plane. The results for all variants are given Table 3 .

Each variant gives 2 habit plane solutions. The following calculations will be done by fixing one of the variants as variant 1 . It can be shown that all other cases are symmetry related to this one. Habit planes calculated for variant 1 are (7 -5 5) and (7 5 -5) in the cubic basis, (7 0 10) and (7 0 -10) in the martensite basis. Figure 7 is a stereographic projection in the $[011]_{\mathrm{B} 2} /[010]_{\mathrm{B} 19}$ direction showing traces of the calculated habit planes. The projection was orientated using the diffraction pattern of the $\mathrm{B} 2$ matrix. Traces of $\left(\begin{array}{lll}7 & -5 & 5\end{array}\right)_{\mathrm{B} 2}$ and $\left(\begin{array}{lll}7 & 5 & -5\end{array}\right)_{\mathrm{B} 2}$ (red lines) planes are consistent with the habit planes directions observed in the bright field picture 6(a). Traces of (7 0 
10) $)_{\mathrm{B} 19}$ and $(70-10)_{\mathrm{B} 19}$ planes were positioned on the projection using the lattice correspondences between the austenite and variant 1, i.e. without rotation. It then become obvious from the projection that there is a few degrees mismatch around the $[011]_{\mathrm{B} 2}$ axis between the pairs of

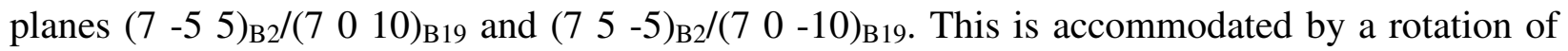
the martensite as shown by the black arrows in Figure 7. The direction of rotation depends on which habit plane is accommodated and explains the difference in the position of the set of B19

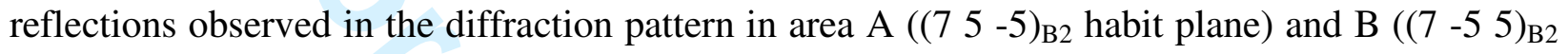
habit plane) in Figures 6(b), 6(e), 8(b) and 8(c). A representation of lattice correspondences and the rotation direction is presented Figure 8(a). One can compute the precise angle of rotation by extracting it from the rotation matrix given by Equation 3.

$$
Q=(a \otimes n+I) U_{i}^{-1}
$$

The rotation matrix $Q$ gives the axis of rotation $\Gamma$ and the angle of rotation $\alpha$ listed in Table 4 . As mentioned before, there are strong indications that the interfacial energy between austenite and martensite contributes strongly to the hysteresis. Consequently, low-hysteresis SMAs are believed to have low energy B2/B19 boundaries. To sustain this assertion, a high resolution study of this interface was attempted. One of the conditions to obtain interpretable high resolution images of the interface is to observe it edge-on along a direction where both phases are in zone orientation along a simple crystallographic axis. This condition is only met along the $[011]_{\mathrm{B} 2} /[010]_{\mathrm{B} 19}$ direction because of the rotation of the martensite around this axis. In addition to this restrictive condition, another experimental difficulty comes from the sensitivity of the interface to beam heating. Under a prolongated exposition to a focused beam the habit plane moves, the martensite being transformed into austenite. 
Figure 9 shows a high resolution micrograph of an interface between a single variant of martensite and austenite in $\mathrm{Ti}_{50} \mathrm{Ni}_{40} \mathrm{Pd}_{10}$ (or 'exact austenite-martensite interface'). The slightly rotated $\left(<4^{\circ}\right)(001)_{\mathrm{B} 19}$ crystallographic planes (upper part) join the $(01-1)_{\mathrm{B} 2}$ planes (lower part) at the interface (habit plane) orientated along the $(7-55)_{\mathrm{B} 2}$ plane. When calculating the geometrical lattice spacing mismatch between the B2 and B19 projected along the trace of this plane, one finds only a small mismatch of $0.36 \%$. In other words, the lattice planes join seamlessly at the interface with very little distortions and no misfit defects were detected. This observation indicates a low energy boundary configuration.

The image simulation added to figure 9 was performed using the multislice method implemented in MacTempas. The orientation relationship between the two superimposed lattices used for the simulation was taken from the GNLTM calculations. A more thorough simulation of the interface would require a DFT calculation of atomic positions near the interface. This would in addition provide a value for the interfacial energy. However, since the habit plane is irrational, periodic DFT cannot be directly implemented and a calculation would require a large supercell and/or an approximation of the habit plane as a rational plane. A quantitative estimation of interfacial energy could also be derived from a HREM image. It would require higher point resolution $(0.17 \mathrm{~nm}$ for this microscope) supported by trough-focus reconstruction and/or aberration corrected microscopy in order to resolve atomic columns along the (01-1) B2 planes (d-spacing $=0.15 \mathrm{~nm}$ ) and to quantify atomic displacements at the interface. Due to this limitation it is also difficult to conclude if the interface is atomically sharp. If there is a transition layer with atomic displacements, it won't exceed a few angstroms leading therefore to small interface energy especially when compared to a classic habit plane as the one observed in the example of Ni-Al (Figure 2). 
3.3 Retained austenite in martensite near compatibility

Several B2/B19 interfaces were also identified in the $\mathrm{Ti}_{50} \mathrm{Ni}_{30} \mathrm{Pd}_{20}, \mathrm{Ti}_{50} \mathrm{Ni}_{32} \mathrm{Pd}_{18}$ and $\mathrm{Ti}_{50} \mathrm{Ni}_{39} \mathrm{Pd}_{11}$ samples. In contrast to the previous case where interfaces were formed by martensite plates retained inside an austenite matrix, the present interfaces originate from very fine parallel lines of retained austenite (few nanometers wide) embedded in a martensite matrix. Figure 10(a) is a bright field image showing several of these lines inside a martensite plate. To elucidate their nature SAED electron diffraction was performed. Figure 10(b) shows the resulting diffraction pattern. It shows two sets of reflections. The brighter spots belong to the B19 phase in [121] zone axis and the weaker spots originate from the line seen in bright field and belonging to the B2 phase in [131] orientation. The relative position of the two set of reflections fits with the model of B2/B19 habit plane presented previously as shown in the simulated diffraction in Figure 10(c). The presence of lines of retained austenite oriented along the habit plane for samples close to $\lambda_{2}=1$ can be explained by the fact that the austenite/martensite transition layer energy must be very small due to their compatibility. The observed austenite regions are a remnant of an incomplete transformation. It is also possible that a small scale fluctuation in composition resulted in a region with $\lambda_{2}$ closer to 1 , or that the observed $\lambda_{2}$ was sufficiently close to 1 that a single interface transformation, accompanied by a delocalized elastic field, is preferred over a twinned austenite-martensite interface.

\subsection{Further discussion on hysteresis}

In a thermo-elastic SMA, the non-chemical part of the energy transmitted to the system during the forward transformation (austenite to martensite) is stored as elastic strain within the 
martensite microstructure. In a perfectly reversible alloy, this elastic energy can be fully recovered upon the reverse transformation. Dissipations mechanisms, however, occur and contribute to the hysteresis. Figure 11 shows the martensite volume fraction evolution of the $\mathrm{Ti}_{50} \mathrm{Ni}_{25} \mathrm{Pd}_{25}$ and $\mathrm{Ti}_{50} \mathrm{Ni}_{40} \mathrm{Pd}_{10}$ samples with temperature (where $\mathrm{M}_{\mathrm{f}}$ was set to 0 for both alloys for easier comparison) to illustrate the evolution of hysteresis. The slopes of the curves can be attributed to stored elastic energy. It is larger for $\mathrm{Ti}_{50} \mathrm{Ni}_{25} \mathrm{Pd}_{25}$ due to the additional interface energy of the LIS laminates and higher misfit at interface between laminated plates when compared to the $\mathrm{Ti}_{50} \mathrm{Ni}_{40} \mathrm{Pd}_{10}$ microstructure composed of mono-variant plates.

The transformation loops show, however, a certain width (hysteresis) which is due to energy dissipation. R.F. Hamilton et al. [27] explains this irreversible component of the energy with two dissipative mechanisms. One is the frictional work spent overcoming the resistance to interfacial motion and the second is due to the dissipation of the stored elastic strain through relaxation of the coherency strains of the martensite-austenite interface. They observed the latter process in TEM with dislocations emitting from a martensite-austenite interface in a Ni-Ti single crystal. Their role is to reduce the remaining internal stress of the martensite variants at the habit plane. These dislocations accumulate over cycling and represent an additional frictional resistance to the habit plane motion. These irreversible processes, which are responsible for the hysteresis, are greatly reduced when $\lambda_{2}=1$ and explain the lower hysteresis observed for $\mathrm{Ti}_{50} \mathrm{Ni}_{40} \mathrm{Pd}_{10}$ in Figure 12.

\section{Conclusion}

In studying the detailed nature of phase compatibility in the $\mathrm{Ti}_{50} \mathrm{Ni}_{50-\mathrm{x}} \mathrm{Pd}_{\mathrm{x}}$ system, four aspects were considered: (a) the evolution of microstructure as the phase compatibility is increased; (b) 
the crystallography of interfaces when one variant of martensite is compatible with the austenite; (c) the atomic arrangement at the interface using HREM; (d) the consequences of these results on the hysteresis.

The drop in hysteresis experienced by shape memory alloys when approaching the compatibility condition $\lambda_{2}=1$ is accompanied with important changes in the microstructure. For alloys with a $\lambda_{2} \geq 1.005$, a typical laminar martensite morphology is observed. It is characterized by elongated plates of martensite composed of a laminate of two martensite variants. The plates also tend to organize themselves as laminates on a higher scale or occasionally along a more complicated self-accommodating pattern. When the compatibility condition is approached, one variant from the laminate becomes dominant until the plate becomes a single variant. The microstructure of $\mathrm{Ti}_{50} \mathrm{Ni}_{39} \mathrm{Pd}_{11}$, which satisfies the compatibility condition, is characterized by the absence of laminates inside the martensite plates and by a complex arrangement of the plates resulting from their self-accommodation and impingement.

The crystallography of the interface between compatible $\mathrm{B} 2$ and $\mathrm{B} 19$ lattices in $\mathrm{Ti}_{50} \mathrm{Ni}_{40} \mathrm{Pd}_{10}$ follow the predictions of the GNLTM. Each variant of martensite grows along two perpendicular habit planes after having rotated in a direction which depends on the selected habit plane.

The high resolution picture of the interface shows that atomic planes join seamlessly at the interface without misfit defects. The B2 and B19 lattices are very little disturbed and no significant transition layer with a strained lattice could be identified. These observations suggest a low energy boundary configuration. In addition, the same alloy shows an extremely low hysteresis.

The low hysteresis observed in alloys satisfying the compatibility condition can be explained by a low dissipation of the elastic energy during transformation. Thanks to a good crystallographic 
fit between the two phases, the stress field is minimized and relaxation mechanisms such as the generation of dislocations are reduced.

\section{Acknowledgements}

The authors would like to thank MULTIMAT "Multi-scale modeling and characterization for phase transformations in advanced materials", a Marie Curie Research Training Network (MRTN-CT-2004-505226) and the FWO project G.0465.05 "The functional properties of shape memory alloys: a fundamental approach" for supporting this work.

\section{References}

[1] J. Cui, Y.S. Chu, O.O. Famodu, Y. Furuya, J. Hattrick-Simpers, R.D. James, A. Ludwig, S. Thienhaus, M. Wuttig, Z. Zhang, I. Takeuchi, Nat. Mater. 5 (2006) 286-290.

[2] J. Ortin, L. Delaey, Int. J. Non Linear Mech. 37 (2002) 1275-1281.

[3] J.M. Ball, R.D. James, Phil. Trans. R. Soc. Lond. A 338 (1992) 389-450.

[4] J.M. Ball, R.D. James, Arch. Ration. Mech. Anal. 100 (1987) 13-52.

[5] R.D. James, Z. Zhang in Magnetism and Structure in Functional Materials (eds L. Mañosa, A. Planes, A. Saxena) (Springer Series in Materials Science, Vol. 79, Springer, New York, 2005).

[6] Z. Zhang, S. Müller, R. D. James, Energy barriers and hysteresis in martensitic phase transformations, submitted to Acta Materialia.

[7] D. Schryvers, M. Yandouzi, D. Holland-Moritz, L. Toth, J. Phys. IV 7 (1997) C5-203.

[8] D. Schryvers, D. Holland-Moritz, Intermetallics 6 (1998) 427-436.

[9] K. Bhattacharya, Microstructure of Martensite, Oxford University Press, 2003.

[10] Q.P. Sun, T.T. Xu, X. Zhang, J. Eng. Mat. Tech. 121 (1999) 38-43. 
[11] M.J. Hÿtch, Ph. Vermaut, J. Malarria, R. Portier, Mater. Sci. Eng. A 273-275 (1999) 266270.

[12] V.P. Sivokha, A.S. Savvinov Voronin, V.N. Khachin, Phys. Met. Metall. 56 (1983) $112-116$.

[13] Y.C. Lo, S.K. Wu, Scr. Metall. Mater. 27 (1992) 1097-1102.

[14] K.F. Hane and T.W. Shield, J. Elast. 59 (2000) 267-318.

[15] P.G. Lindquist, PhD thesis, University of Illinois at Urbana-Champaign (1988).

[16] M. Nishida, T. Hara, Y. Morizono, A. Ikeya, H. Kijima, A. Chiba, Acta Mater. 45 (1997) 4847-4853.

[17] K.A. Bywater, J.W. Christian, Philos. Mag. 25-26 (1972) 1249-1273.

[18] T. Tadaki, C.M. Wayman, Metallography 15 (1982) 247-258.

[19] T. Saburi, T. Komatsu, S. Nenno, Y. Watanabe, J. Less-Common Met., 118 (1986), 217-226.

[20] W.J. Moberly, J.L. Proft, T.W. Duerig, R. Sinclair, Mater. Sci. Forum 56-58 (1990) 605-610.

[21] K. Madangopal, Acta Mater. 45 (1997) 5347-5365.

[22] S. Miyazaki, K. Otsuka, C.M. Wayman, Acta Metall. 37 (1989) 1873-1884.

[23] T. Saburi, Y. Watanabe, S. Nenno, ISIJ Int. 29 (1989) 405-411.

[24] R. Delville, D. Schryvers, Z. Zhang, R.D. James, Scr. Mater., 6 (2009) 293-296.

[25] Ph. Boullay, D. Schryvers, J.M. Ball, Acta Mater. 51 (2002) 1421 - 1436.

[26] D. Schryvers, Phil. Mag. A 68 (1993) 1017-1032.

[27] R.F. Hamilton, H. Sehitoglu, Y. Chumlyakov, H.J. Maier, Acta Mater. 52 (2004) 33833402 . 


\begin{tabular}{cccccccc}
\hline Alloys & $a_{0}(\AA)$ & $a(\AA)$ & $b(\AA)$ & $c(\AA)$ & $\lambda_{2}$ & $\theta_{c}(K)$ & $H(K)$ \\
\hline $\mathrm{Ti}_{50} \mathrm{Ni}_{43} \mathrm{Pd}_{7}$ & 3.0318 & 2.8493 & 4.2747 & 4.5474 & 0.9970 & -20 & 26 \\
$\mathrm{Ti}_{50} \mathrm{Ni}_{41} \mathrm{Pd}_{9}$ & 3.0469 & 2.8461 & 4.3036 & 4.5827 & 0.9988 & 40 & 18 \\
$\mathrm{Ti}_{50} \mathrm{Ni}_{40} \mathrm{Pd}_{10}$ & 3.0471 & 2.8436 & 4.3083 & 4.5934 & 0.9998 & 23 & 6 \\
$\mathrm{Ti}_{50} \mathrm{Ni}_{39} \mathrm{Pd}_{11}$ & 3.0499 & 2.8304 & 4.3135 & 4.6041 & 1.0001 & 25 & 13 \\
$\mathrm{Ti}_{50} \mathrm{Ni}_{32} \mathrm{Pd}_{18}$ & 3.0556 & 2.8194 & 4.3429 & 4.6281 & 1.0050 & 113 & 22 \\
$\mathrm{Ti}_{50} \mathrm{Ni}_{30} \mathrm{Pd}_{20}$ & 3.0508 & 2.8202 & 4.3404 & 4.6126 & 1.0060 & 103 & 26 \\
$\mathrm{Ti}_{50} \mathrm{Ni}_{25} \mathrm{Pd}_{25}$ & 3.0625 & 2.8074 & 4.3614 & 4.6667 & 1.0070 & 189 & 32 \\
\hline
\end{tabular}

Table 1 - Lattice parameters of the austenite B2 phase $\left(a_{0}\right)$ and the martensite $\mathrm{B} 19$ phase $(a, b, c)$ in Ångstrom. The middle eigenvalue $\lambda_{2}$ is equal to $b /\left(\sqrt{ } 2 \cdot a_{0}\right)$. It decreases as Pd decreases for the series studied. $\theta_{\mathrm{c}}$ is defined as the average of the 4 characteristic transformation temperatures, $\theta_{c}=\left(A_{s}+A_{f}+M_{s}+M_{f}\right) / 4$ and the hysteresis as $H=\left(A_{s}+A_{f}-M_{s}-M_{f}\right) / 2$.

\begin{tabular}{cccccc}
\hline Type of twins & $x$ & $K_{1}$ & $\eta_{1}$ & Twin ratio $\lambda$ & $\lambda_{2}$ \\
\hline \multirow{3}{*}{111} type I & 9 & & $<1-0.21-0.80>$ & $\varnothing$ & 0.9988 \\
& 20 & $\{111\}$ & $<1-0.23-0.77>$ & 0.003 & 1.0001 \\
& 9 & $\{0.59-0.18-1\}$ & $<1-0.26-0.74>$ & 0.15 & 1.0060 \\
\hline \multirow{3}{*}{$<211>$ type II } & 11 & $\{0.60-0.20-1\}$ & $<211>$ & $\varnothing$ & 0.9988 \\
& 20 & $\{0.63-0.26-1\}$ & & 0.004 & 1.0001 \\
& 9 & & & 0.18 & 1.0060 \\
\hline \multirow{3}{*}{011} compound & 11 & $\{011\}$ & $<01-1>$ & 0.019 & 0.9988 \\
& 20 & & & $\varnothing$ & 1.0001 \\
& & & & $\varnothing$ & 1.0060 \\
\hline
\end{tabular}

Table 2 - Twinning modes and twin ratios for $\mathrm{Ti}_{50} \mathrm{Ni}_{50-\mathrm{x}} \mathrm{Pd}_{\mathrm{x}}, x=9,11,20$, calculated from the GNLTM. $K_{1}$ is the twinning plane and $\eta_{1}$ the shear direction. The twin ratio is defined as the width ratio between two martensite variants accommodating a habit plane with the austenite. 


\begin{tabular}{|c|c|c|c|c|}
\hline & \multicolumn{2}{|c|}{ Habit plane 1} & \multicolumn{2}{|c|}{ Habit plane 2} \\
\hline & $\mathrm{B} 2$ basis & B19 basis & B2 basis & B19 basis \\
\hline U1 & $(7-55)$ & & $(75-5)$ & \\
\hline $\mathrm{U} 2$ & $\left(\begin{array}{lll}-7 & 5 & 5\end{array}\right)$ & & $(755)$ & \\
\hline U3 & $(57-5)$ & $\left(\begin{array}{lll}7 & 0 & 10\end{array}\right)$ & $(-575)$ & $\left(\begin{array}{lll}7 & 0 & -10\end{array}\right)$ \\
\hline $\mathrm{U} 4$ & $(5-75)$ & & $(575)$ & \\
\hline U5 & $(-557)$ & & $(5-57)$ & \\
\hline U6 & $(55-7)$ & & $\left(\begin{array}{l}5 \\
5\end{array} 7\right)$ & \\
\hline
\end{tabular}

Table 3 - Calculated habit planes for the 6 variants of martensite $\left(U_{1}-U_{6}\right)$. The results are given in the austenite (B2) and martensite (B19) basis. Irrational plane indices are approximated to the closest set of integers.

\begin{tabular}{|c|c|c|c|}
\hline Variant & Habit plane & Angle $\alpha$ & $\begin{array}{c}\text { Rotation axis } \\
\Gamma\end{array}$ \\
\hline \multirow{2}{*}{ U1 } & $(7-55)$ & $-3.8^{\circ}$ & \multirow{2}{*}{ [011] } \\
\hline & $(75-5)$ & $3.8^{\circ}$ & \\
\hline \multirow{2}{*}{ U2 } & $(-755)$ & $-3.8^{\circ}$ & \multirow{2}{*}{ [01-1] } \\
\hline & (7 55 ) & $3.8^{\circ}$ & \\
\hline \multirow{2}{*}{ U3 } & $(57-5)$ & $-3.8^{\circ}$ & \multirow{2}{*}{ [101] } \\
\hline & $(-575)$ & $3.8^{\circ}$ & \\
\hline \multirow{2}{*}{ U4 } & $(5-7$ - 5) & $-3.8^{\circ}$ & \multirow{2}{*}{ [10-1] } \\
\hline & (5 75 ) & $3.8^{\circ}$ & \\
\hline \multirow{2}{*}{ U5 } & $(-557)$ & $-3.8^{\circ}$ & \multirow{2}{*}{ [110] } \\
\hline & $(5-57)$ & $3.8^{\circ}$ & \\
\hline \multirow{2}{*}{ U6 } & $(55-7)$ & $-3.8^{\circ}$ & \multirow{2}{*}{ [1-10] } \\
\hline & (5 557 ) & $3.8^{\circ}$ & \\
\hline
\end{tabular}

Table 4 - Angle and axis of rotation extracted from the rotation matrix $Q$ for the two habit planes solutions for the 6 variants. 
Figure 1 - Width of hysteresis vs. $\lambda_{2}$ for the $\mathrm{Ti}_{50} \mathrm{Ni}_{50-\mathrm{x}} \mathrm{Pd}_{\mathrm{x}}$ bulk alloys system. The atomic percentage of $\mathrm{Pd}$ is indicated by $\mathrm{Pd}_{\mathrm{x}}$.

Figure 2 - A high resolution transmission electron micrograph of an austenite-martensite interface in splat-cooled $\mathrm{Ni}_{62.5} \mathrm{Al}_{37.5}$. The inset shows a magnification of the rectangular area revealing the atomic resolution near the interface.

Figure 3 - Evolution of microstructure with composition is shown in the bright field images (a)(c). Figure (a) shows internally twinned martensite plates in $\mathrm{Ti}_{50} \mathrm{Ni}_{25} \mathrm{Pd}_{25}$, (b) shows a plate in $\mathrm{Ti}_{50} \mathrm{Ni}_{30} \mathrm{Pd}_{20}$ with a smaller twin ratio, (c) shows an example of microstructure in $\mathrm{Ti}_{50} \mathrm{Ni}_{39} \mathrm{Pd}_{11}$ composed of a mosaic of twinless martensite plates noted E, F, G, H and a group of compound twins (D). SAD patterns (d, e) correspond to plates A and B in Figure (a) showing $\{111\}$ type I twins with the incident electron beam B//[1-10]I for (d) and B//[01-1]I for (e). SAD pattern (f) was taken over the circled area D and belongs to (011) compound twins observed in the [001] direction. The two variants are indexed I and II.

\footnotetext{
Figure 4 - Example of microstructure in a compatible alloy, $\mathrm{Ti}_{50} \mathrm{Ni}_{39} \mathrm{Pd}_{11}$. The martensite plates exhibit no internal twin laminates. Some boundaries between plates in $\mathrm{Ti}_{50} \mathrm{Ni}_{39} \mathrm{Pd}_{11}$ were found to be in twin orientation. Figure (c)-(e) are SAD patterns taken from the circled areas C, D, E respectively and shows $\{111\}$ type I twin $(\mathrm{C}, \mathrm{E})$ and $<211>$ type II twin (D). The zone axis (ZA) of the diffraction patterns are indicated on the figure.
} 
Figure 5 - DSC curves of $\mathrm{Ti}_{50} \mathrm{Ni}_{40} \mathrm{Pd}_{10}$. The cubic to orthorhombic phase transformation exhibits a very small hysteresis measured as $H=\left(A_{s}+A_{f}-M_{s}-M_{f}\right) / 2$.

Figure 6 - Microstructure and crystallography of $\mathrm{Ti}_{50} \mathrm{Ni}_{40} \mathrm{Pd}_{10}$. (a) Bright field micrograph showing plates of martensite aligned along the two perpendicular directions of habit planes inside an austenite matrix. (b) SAD patterns taken over the two circled areas A and B and the corresponding simulations using parameters derived from the GNLTM. Both series show two sets of reflections corresponding to the $[011]_{\mathrm{B} 2} /[010]_{\mathrm{B} 19}$ zone axis patterns. The B19 set of reflections is slightly rotated relatively to the B2 set with an opposite angle for the A and B areas.

Figure 7 - Trace analysis of habit planes in $\mathrm{Ti}_{50} \mathrm{Ni}_{40} \mathrm{Pd}_{10}$. The traces of the two calculated habit planes for variant 1 are drawn for the B2 (red) and B19 (blue) phases in the $[011]_{\mathrm{B} 2} /[010]_{\mathrm{B} 19}$ directions, before rotation of the martensite, using only lattice correspondences. The B2 traces directions are consistent with the habit planes directions observed in Figure 6(a). A small angle misfit is observed between the $\left(\begin{array}{lll}7 & 5 & -5\end{array}\right)_{\mathrm{B} 2} /\left(\begin{array}{lll}7 & 0 & -10\end{array}\right)_{\mathrm{B} 19}$ and the $\left(\begin{array}{lll}7 & -5 & 5\end{array}\right)_{\mathrm{B} 2} /\left(\begin{array}{lll}7 & 0 & 10\end{array}\right)_{\mathrm{B} 19}$ planes traces. This is accommodated by a rotation of the martensite as shown by the black arrows.

Figure 8 - Lattice correspondences and martensite rotation. (a) is 3D representation of lattice correspondences for variant 1 . The white arrow represents the observation axis of Figure 6(a). Depending on the habit plane, the martensite rotates in the ' 1 ' or ' 2 ' directions. The rotation axis is $[011]_{\mathrm{B} 2}$. (b) and (c) are enlargements of the diffraction patterns from area A and B in Figure 6(b) and 6(e). The blue lines show how the set of B19 reflections was rotated in the ' 1 ' direction 
(Figure (b)) or '2' direction (Figure (c)) relatively to the set of B2 reflections (red lines). The rotation angle is measured at $3.7^{\circ}+/-0.1$, in good agreement with the calculated value of $3.8^{\circ}$.

Figure 9 - HREM picture of an exact austenite-martensite interface. The upper part is the B19 phase in [010] orientation, the lower part is the B2 phase in [011] orientation. A simulation of the interface and the trace of the habit plane are added to the picture. The $(011)_{\mathrm{B} 19}$ (blue line) and $(01-1)_{\mathrm{B} 2}$ (red line) planes joins seamlessly at the interface despite the small rotation of the martensite and a misfit in lattice plane spacing as indicated in the enlargement of the inset.

Figure 10 - Figure (a) is a bright field image showing lines of retained austenite in $\mathrm{Ti}_{50} \mathrm{Ni}_{30} \mathrm{Pd}_{20}$. The diffraction pattern in Figure (b) shows two sets of reflections. One comes from the beam diffracted by the martensite in [121] zone axis and the other from retained austenite in [131] zone axis. Figure (c) is a simulated diffraction pattern using the habit plane parameters given by the GNLTM. The blue and red sets of reflections correspond to the B19 martensite and B2 austenite, respectively.

Figure 11 - Martensite volume fraction $\mathrm{f}$ vs. temperature for the $\mathrm{Ti}_{50} \mathrm{Ni}_{25} \mathrm{Pd}_{25}$ and $\mathrm{Ti}_{50} \mathrm{Ni}_{40} \mathrm{Pd}_{10}$ alloys illustrating the contribution to the hysteresis loop. The slope of the curve is attributed to the stored elastic energy which is recoverable and the width of the loop is due to energy dissipation which constitutes the hysteresis. 


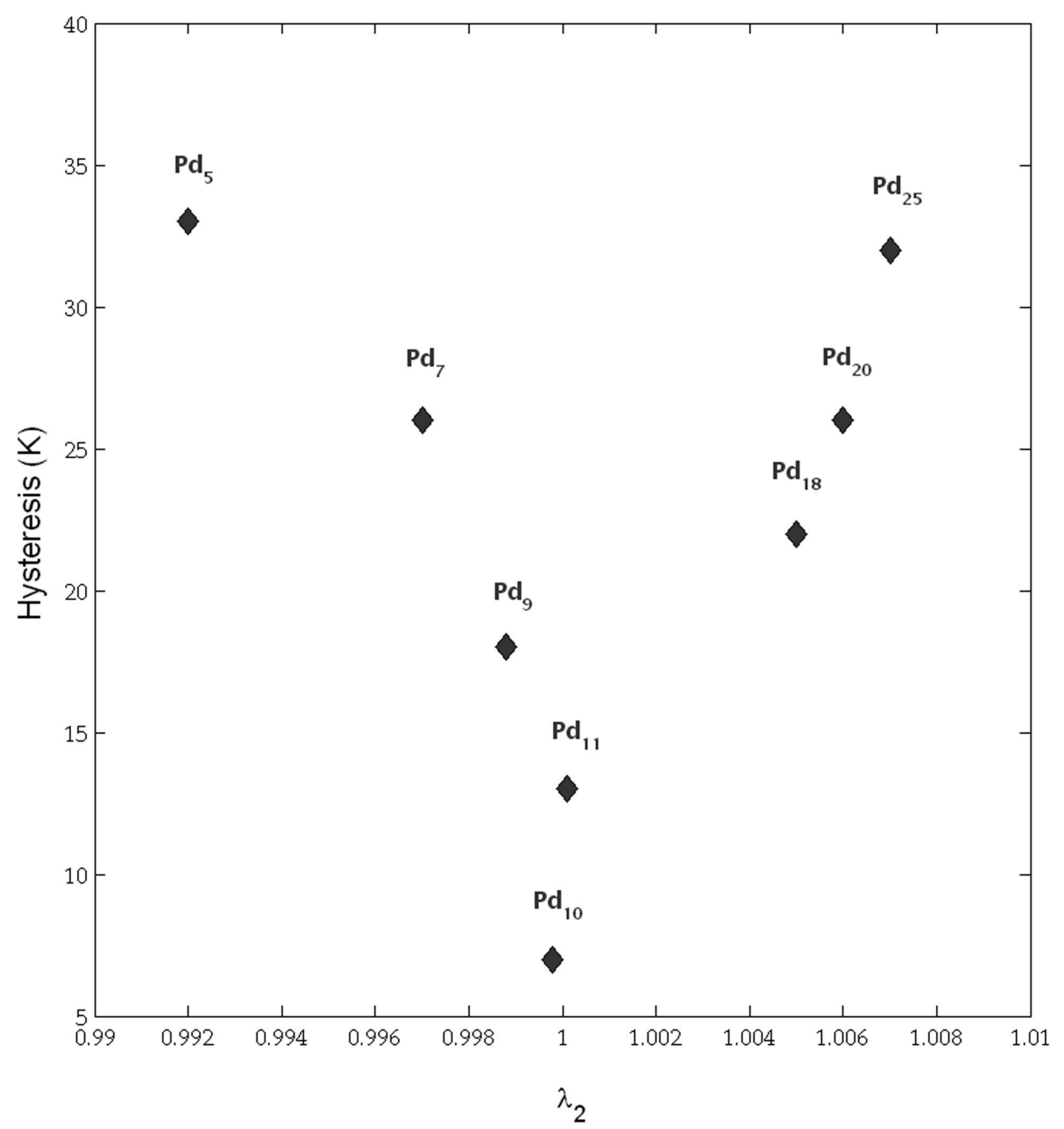

Figure 1 - Width of hysteresis vs. $\lambda_{2}$ for the $\mathrm{Ti}_{50} \mathrm{Ni}_{50-x} \mathrm{Pd}_{\mathrm{x}}$ bulk alloys system. The atomic percentage of $\mathrm{Pd}$ is indicated by $\mathrm{Pd}_{\mathrm{x}}$. $169 \times 179 \mathrm{~mm}(300 \times 300 \mathrm{DPI})$ 
Figure 2 - A high resolution transmission electron micrograph of an austenite-martensite interface in splat-cooled $\mathrm{Ni}_{62.5} \mathrm{Al}_{37.5}$. The inset shows a magnification of the rectangular area revealing the atomic resolution near the interface. $169 \times 108 \mathrm{~mm}(600 \times 600 \mathrm{DPI})$ 


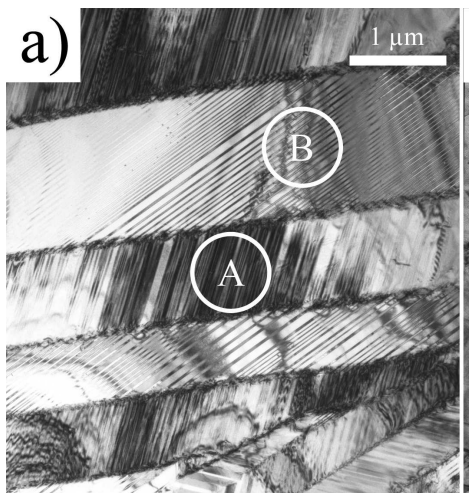

b)

$$
\mathrm{Ti}_{50} \mathrm{Ni}_{25} \mathrm{Pd}_{25} \lambda_{2}=1.0070
$$

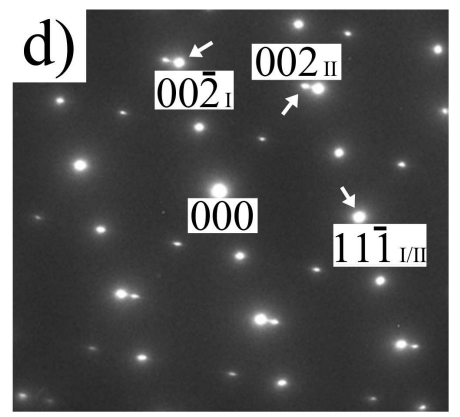

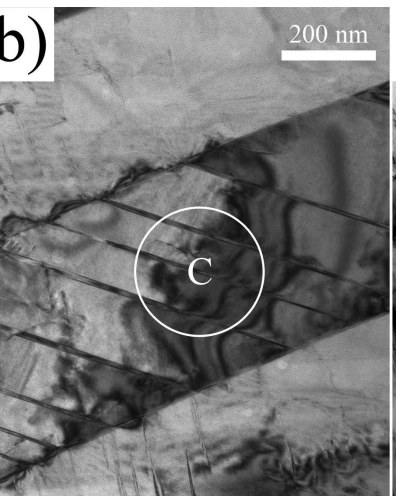

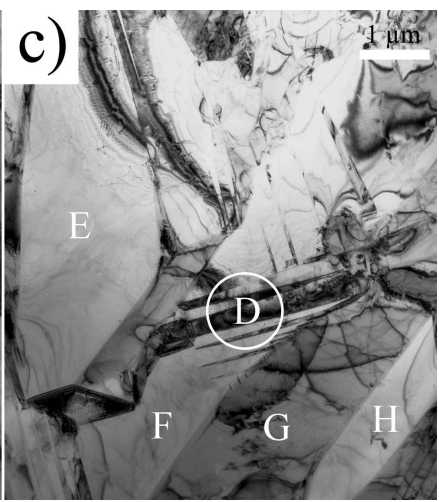

$\mathrm{Ti}_{50} \mathrm{Ni}_{30} \mathrm{Pd}_{20} \lambda_{2}=1.0050$
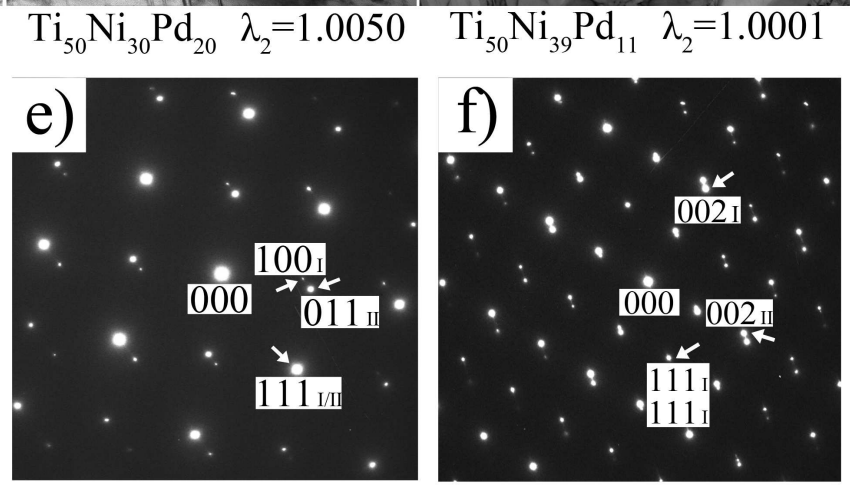

Figure 3 - Evolution of microstructure with composition is shown in the bright field images (a)-(c).

Figure (a) shows internally twinned martensite plates in $\mathrm{Ti}_{50} \mathrm{Ni}_{25} \mathrm{Pd}_{25}$, (b) shows a plate in $\mathrm{Ti}_{50} \mathrm{Ni}_{30} \mathrm{Pd}_{20}$ with a smaller twin ratio, (c) shows an example of microstructure in $\mathrm{Ti}_{50} \mathrm{Ni}_{39} \mathrm{Pd}_{11}$ composed of a mosaic of twinless martensite plates noted $E, F, G, H$ and a group of compound twins (D). SAD patterns ( $d, e)$ correspond to plates $A$ and $B$ in Figure (a) showing $\{111\}$ type $I$ twins with the incident electron beam $B / /[1-10]_{I}$ for $(d)$ and $B / /[01-1]_{I}$ for (e). SAD pattern (f) was taken over the circled area D and belongs to (011) compound twins observed in the [001] direction. The two variants are indexed I and II. $127 \times 95 \mathrm{~mm}(600 \times 600 \mathrm{DPI})$ 


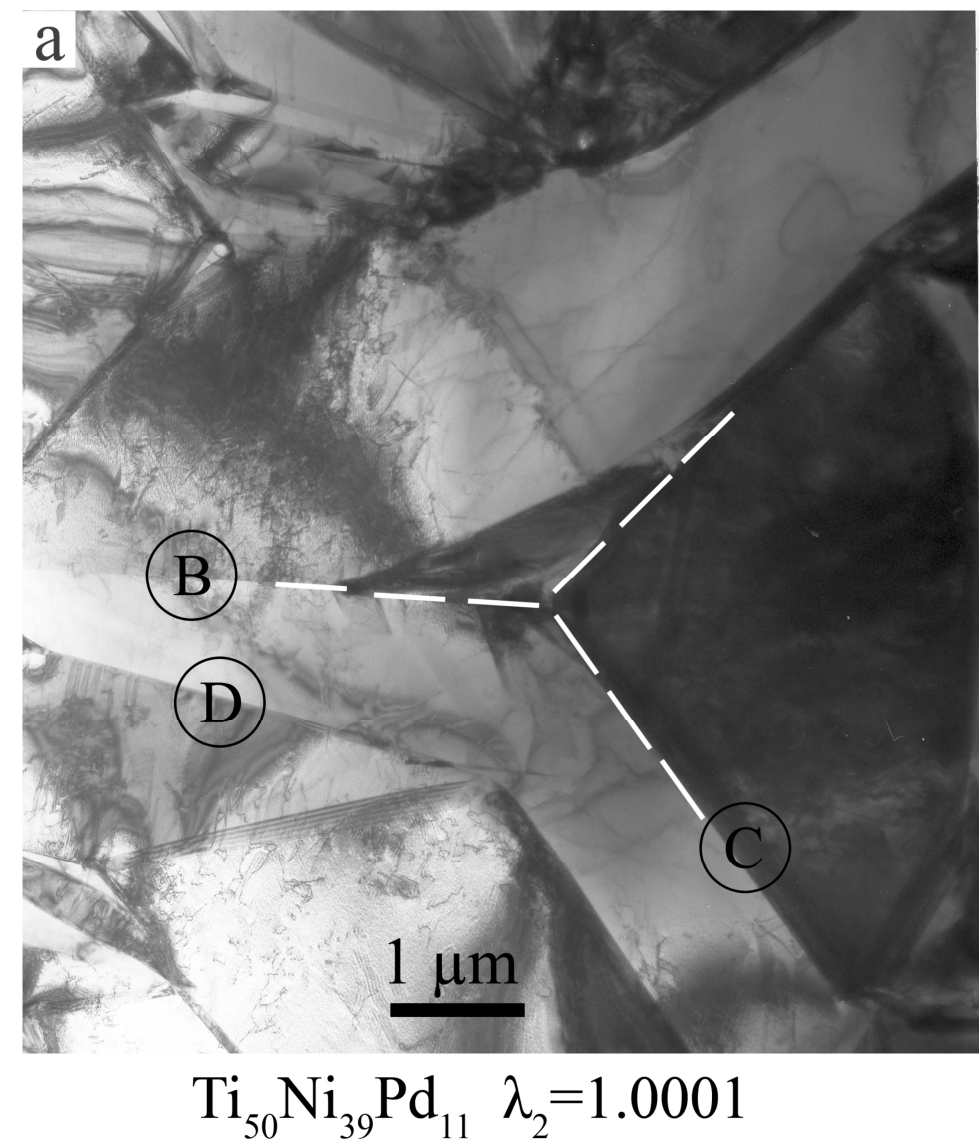

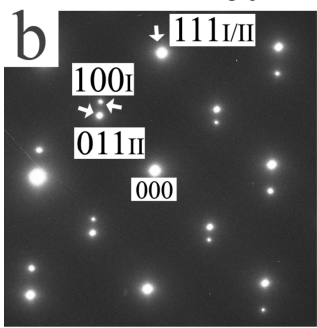

$\{111\}$ type I ZA [1-10]

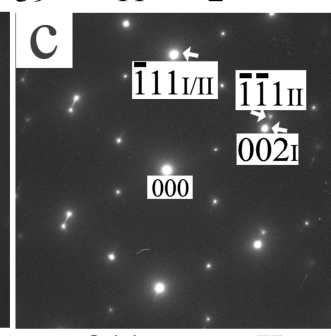

$<211>$ type II

ZA [110]

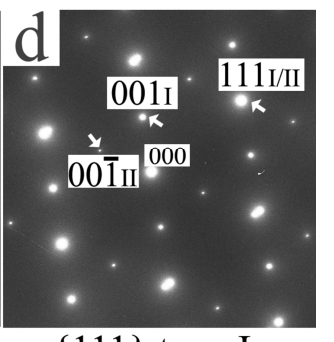

$\{111\}$ type I ZA [01-1]

Figure 4 - Example of microstructure in a compatible alloy, $\mathrm{Ti}_{50} \mathrm{Ni}_{39} \mathrm{Pd}_{11}$. The martensite plates exhibit no internal twin laminates. Some boundaries between plates in $\mathrm{Ti}_{50} \mathrm{Ni}_{39} \mathrm{Pd}_{11}$ were found to be in twin orientation. Figure (c)-(e) are SAD patterns taken from the circled areas C, D, E respectively and shows $\{111\}$ type I twin $(C, E)$ and $<211>$ type II twin (D). The zone axis (ZA) of the diffraction patterns are indicated on the figure. $109 \times 177 \mathrm{~mm}(600 \times 600 \mathrm{DPI})$ 


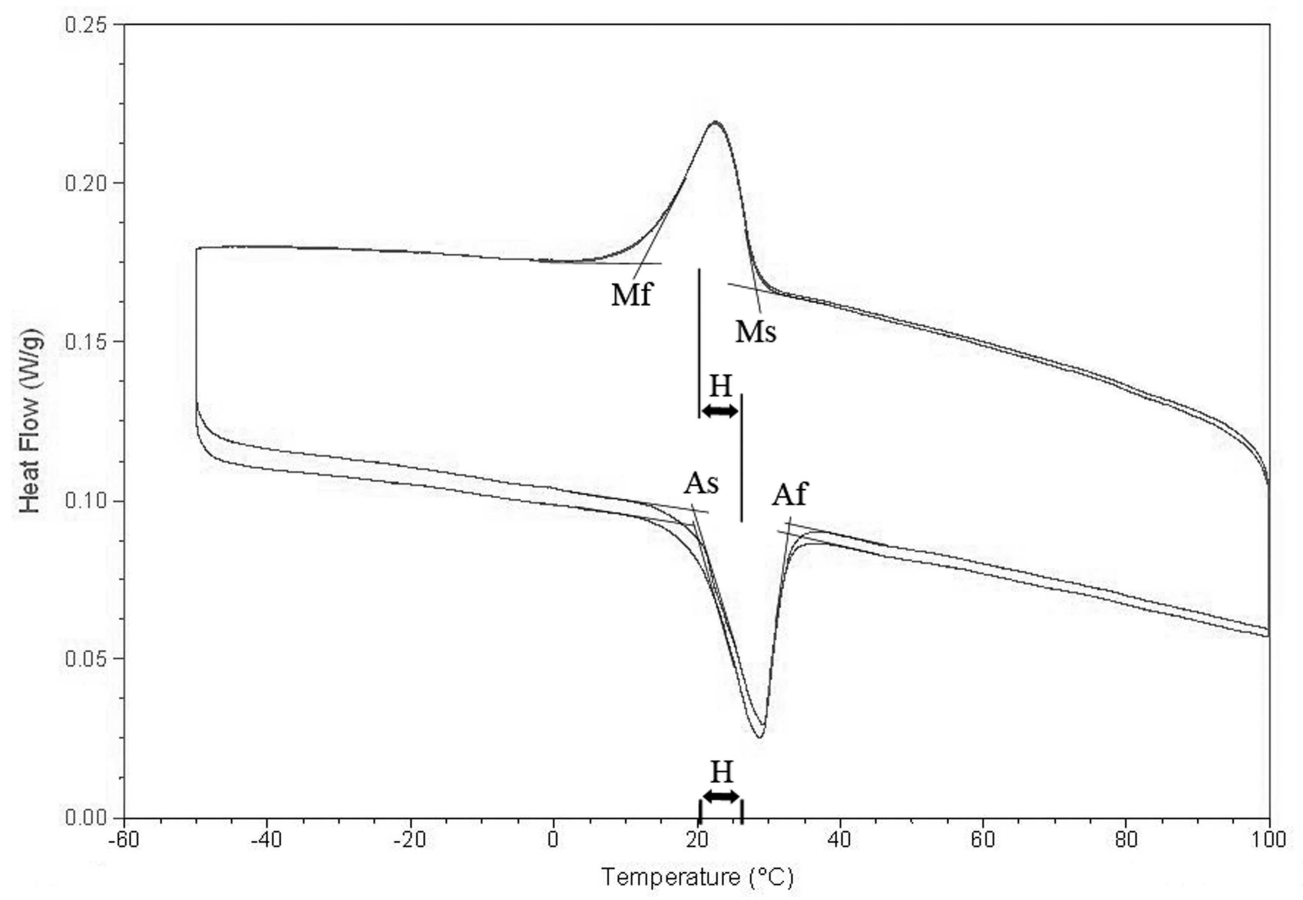

Figure 5 - DSC curves of $\mathrm{Ti}_{50} \mathrm{Ni}_{40} \mathrm{Pd}_{10}$. The cubic to orthorhombic phase transformation exhibits a very small hysteresis measured as $\mathrm{H}=(\mathrm{As}+\mathrm{Af}-\mathrm{Ms}-\mathrm{Mf}) / 2$. $254 \times 173 \mathrm{~mm}(300 \times 300 \mathrm{DPI})$ 
Figure 6 - Microstructure and crystallography of $\mathrm{Ti}_{50} \mathrm{Ni}_{40} \mathrm{Pd}_{10}$. (a) Bright field micrograph showing plates of martensite aligned along the two perpendicular directions of habit planes inside an austenite matrix. (b) SAD patterns taken over the two circled areas A and B and the corresponding simulations using parameters derived from the GNLTM. Both series show two sets of reflections corresponding to the $[011]_{\mathrm{B} 2} /[010]_{\mathrm{B} 19}$ zone axis patterns. The $\mathrm{B} 19$ set of reflections is slightly rotated relatively to the $B 2$ set with an opposite angle for the $A$ and $B$ areas. $127 \times 175 \mathrm{~mm}(300 \times 300 \mathrm{DPI})$ 
Figure 7 - Trace analysis of habit planes in $\mathrm{Ti}_{50} \mathrm{Ni}_{40} \mathrm{Pd}_{10}$. The traces of the two calculated habit planes for variant 1 are drawn for the B2 (red) and B19 (blue) phases in the $[011]_{\mathrm{B} 2} /[010]_{\mathrm{B} 19}$ directions, before rotation of the martensite, using only lattice correspondences. The B2 traces directions are consistent with the habit planes directions observed in Figure 6(a). A small angle misfit is observed between the $(75-5)_{\mathrm{B} 2} /(70-10)_{\mathrm{B} 19}$ and the $(7-55)_{\mathrm{B} 2} /\left(\begin{array}{lll}7 & 0 & 10\end{array}\right)_{\mathrm{B} 19}$ planes traces. This is accommodated by a rotation of the martensite as shown by the black arrows. $169 \times 167 \mathrm{~mm}(300 \times 300 \mathrm{DPI})$ 

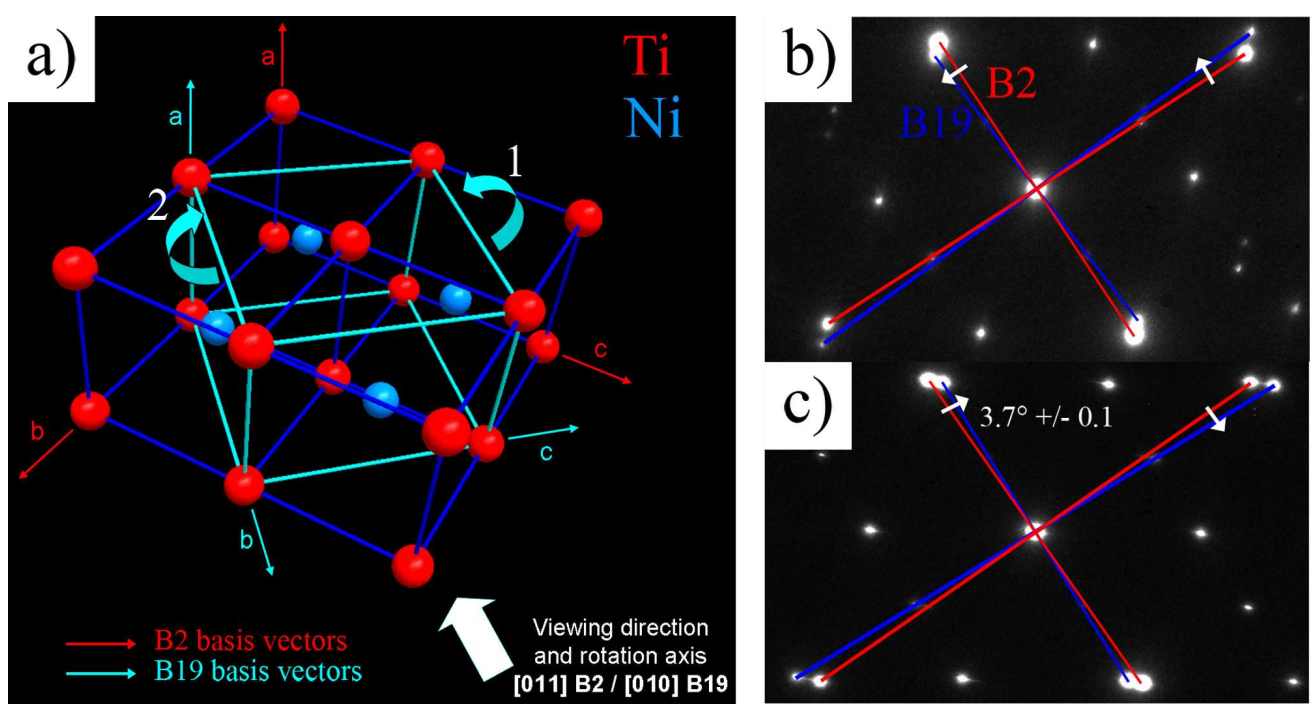

Figure 8 - Lattice correspondences and martensite rotation. (a) is 3D representation of lattice correspondences for variant 1 . The white arrow represents the observation axis of Figure 6(a). Depending on the habit plane, the martensite rotates in the ' 1 ' or ' 2 ' directions. The rotation axis is $[011]_{\mathrm{B} 2}$. (b) and (c) are enlargements of the diffraction patterns from area A and B in Figure 6(b) and 6(e). The blue lines show how the set of B19 reflections was rotated in the ' 1 ' direction (Figure (b)) or ' $2^{\prime}$ ' direction (Figure (c)) relatively to the set of B2 reflections (red lines). The rotation angle is measured at $3.7^{\circ}+/-0.1$, in good agreement with the calculated value of $3.8^{\circ}$. $169 \times 89 \mathrm{~mm}(300 \times 300 \mathrm{DPI})$ 


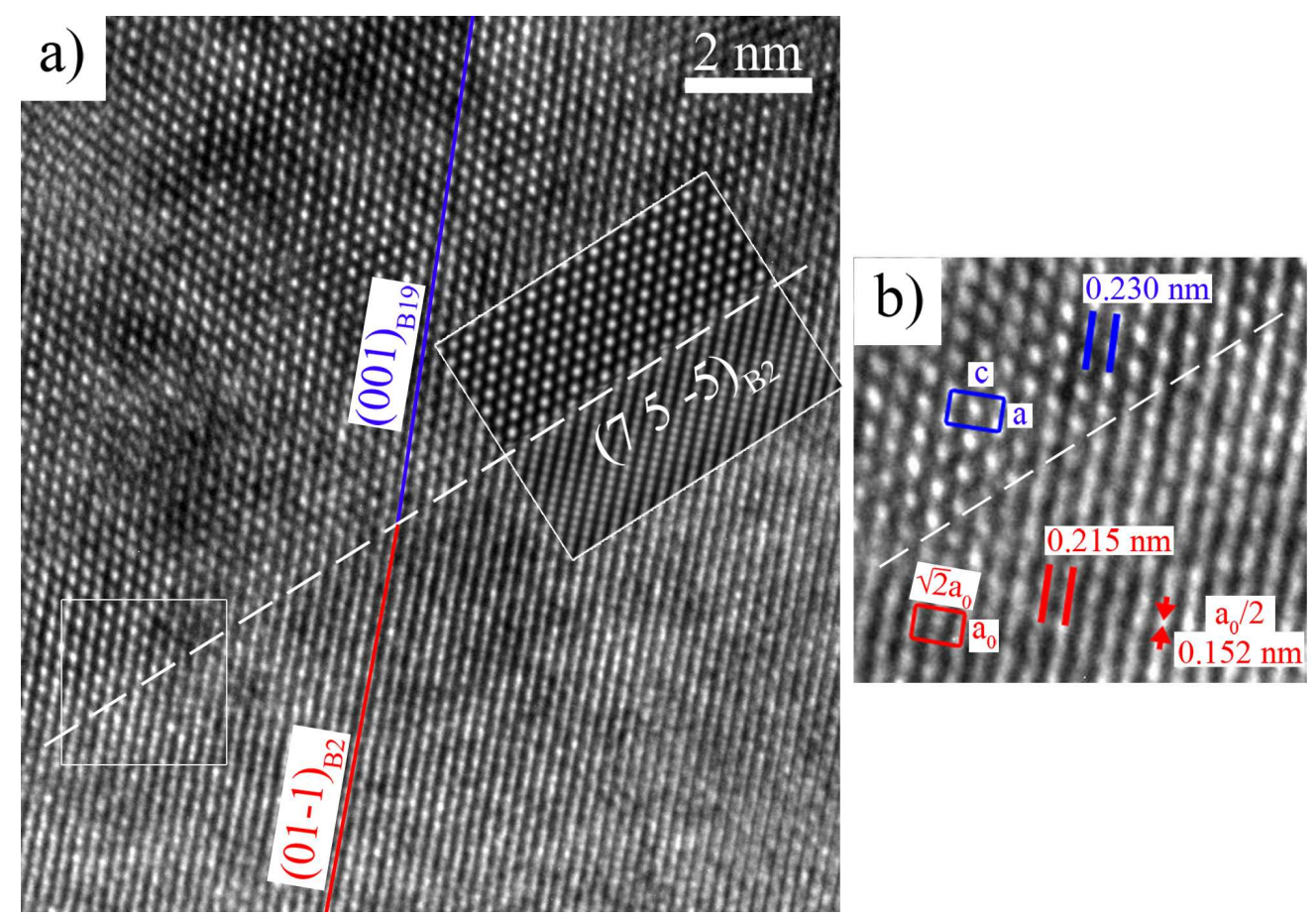

Figure 9 - HREM picture of an exact austenite-martensite interface. The upper part is the B19 phase in [010] orientation, the lower part is the B2 phase in [011] orientation. A simulation of the interface and the trace of the habit plane are added to the picture. The (011) $)_{B 19}$ (blue line) and (01-

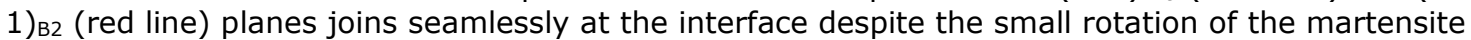
and a misfit in lattice plane spacing as indicated in the enlargement of the inset. $169 \times 117 \mathrm{~mm}(300 \times 300 \mathrm{DPI})$ 


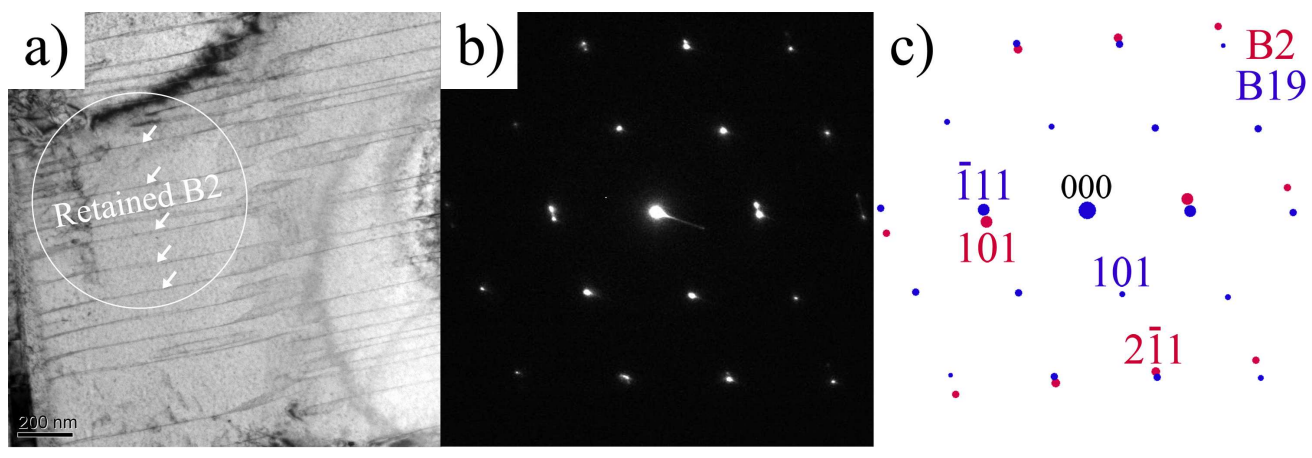

Figure 10 - Figure (a) is a bright field image showing lines of retained austenite in $\mathrm{Ti}_{50} \mathrm{Ni}_{30} \mathrm{Pd}_{20}$. The diffraction pattern in Figure (b) shows two sets of reflections. One comes from the beam diffracted by the martensite in [121] zone axis and the other from retained austenite in [131] zone axis. Figure (c) is a simulated diffraction pattern using the habit plane parameters given by the GNLTM. The blue and red sets of reflections correspond to the B19 martensite and B2 austenite, respectively. $254 \times 84 \mathrm{~mm}(300 \times 300$ DPI $)$ 
Figure 11 - Martensite volume fraction $\mathrm{f}$ vs. temperature for the $\mathrm{Ti}_{50} \mathrm{Ni}_{25} \mathrm{Pd}_{25}$ and $\mathrm{Ti}_{50} \mathrm{Ni}_{40} \mathrm{Pd}_{10}$ alloys illustrating the contribution to the hysteresis loop. The slope of the curve is attributed to the stored elastic energy which is recoverable and the width of the loop is due to energy dissipation which constitutes the hysteresis. $120 \times 113 \mathrm{~mm}(300 \times 300 \mathrm{DPI})$

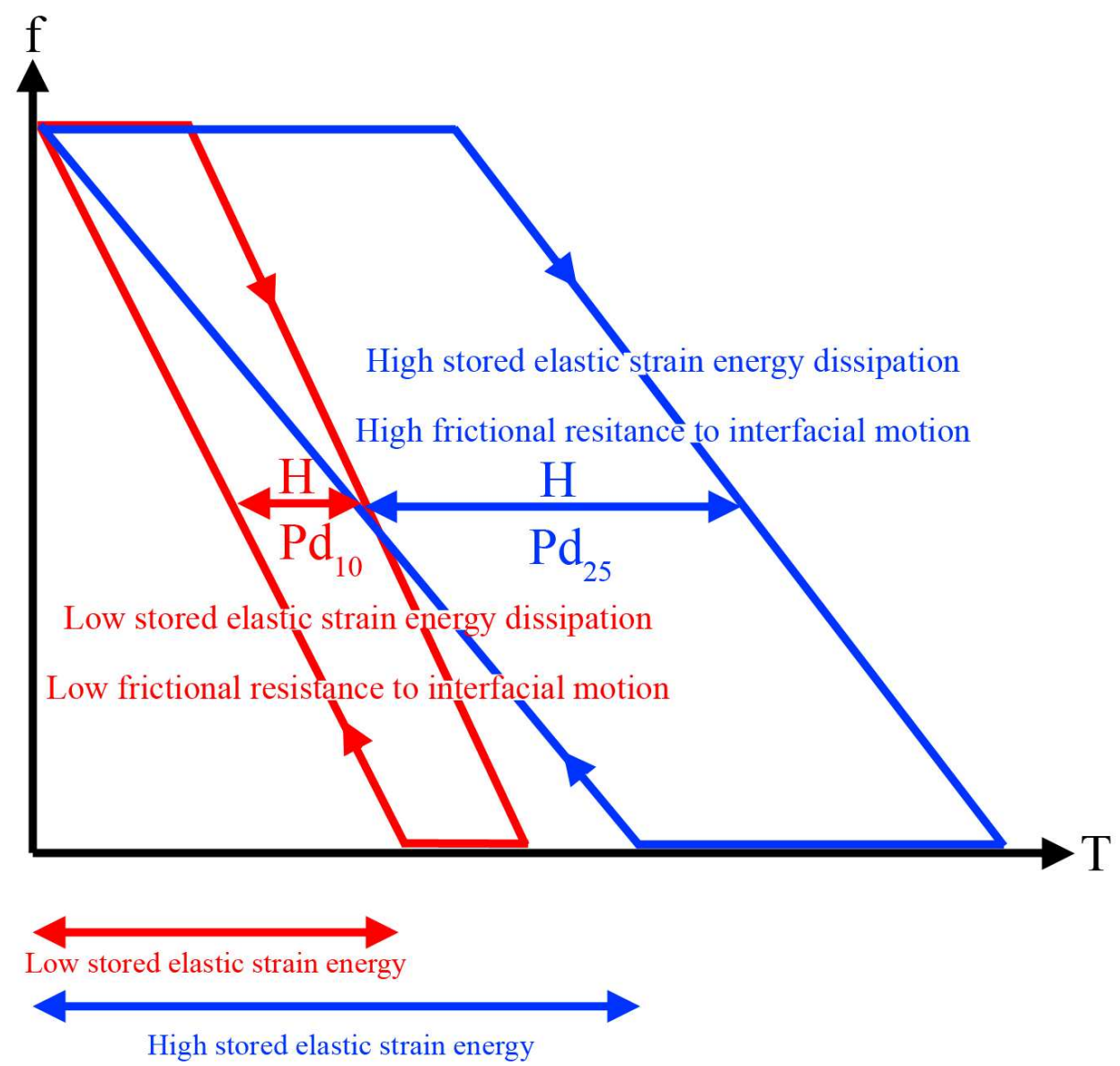

High stored elastic strain energy 